\title{
Validation of Reference Genes for Quantitative Real-time PCR in Diaphanosoma Celebensis: For Chemical Exposure Conditions and Different Ages
}

\section{Young-Mi Lee ( $\nabla$ ymlee70@smu.ac.kr)}

Sangmyung University

\section{Soyeon In}

Sangmyung University

\section{Se-Joo Kim}

Korea Research Institute Bioscience and Biotechnology

\section{Eun-Ji Won}

Hanyang University

\section{Hayoung Cho}

Sangmyung University

Ryeo-Ok Kim

Sangmyung University

\section{Research Article}

Keywords: quantitative real-time PCR, Diaphanosoma celebensis, chemical exposure conditions

Posted Date: September 1st, 2021

DOI: https://doi.org/10.21203/rs.3.rs-847536/v1

License: (c) (i) This work is licensed under a Creative Commons Attribution 4.0 International License. Read Full License 


\section{Abstract}

Real-time quantitative reverse transcription polymerase chain reaction (qRT-PCR), a primary approach for evaluating gene expression, requires an appropriate normalization strategy to rule out variations in gene expression among samples. The best option is to use a reference gene whose expression level is stable across various experimental conditions to compare the mRNA levels of a target gene. However, there is limited information on how the reference gene is differentially expressed at different ages (growth) in small invertebrates with notable changes such as molting. In this study, expression profiles of nine candidate reference genes from the brackish water flea, Diaphanosoma celebensis, were evaluated under diverse exposure to toxicants and according to growth. As a result, four different algorithms showed similar stabilities of genes for chemical exposures in the case of limited conditions using the same developmental stage (e.g., adult), while the results according to age showed a significantly different pattern in suite of candidate reference genes. This affected the results of genes ECRA and GST, which are involved in development and detoxification mechanisms, respectively. Our finding is the first step towards establishing a standardized real-time qRT-PCR analysis of this environmentally important invertebrate that has potential for aquatic ecotoxicology, particularly in estuarine environments.

\section{Introduction}

Environmental pollutants, such as heavy metals and persistent organic pollutants, have been of great concern because of their persistence in aquatic environments and harmful effects on aquatic organisms ${ }^{1,2}$. In order to manage pollutants in aquatic environments, the diagnosis of biological responses is considered to be a significant factor in identifying the pollution or for further actions such as setting the guidelines ${ }^{3}$. Gene expression in the cell is the first step in the biological response to environmental stressors, resulting in biochemical, morphological, and functional changes. Reverse transcription - polymerase chain reaction (RT-PCR) is a highly sensitive and reproducible method for investigating gene expression ${ }^{4}$. In recent decades, RT-PCR has become a leading technique with the advantages of high sensitivity, specificity, and repeatability in several studies conducted in the field, including aquatic environments ${ }^{5}$. However, since variations in the initial RNA amount and efficiency of cDNA synthesis can lead to errors in RT-PCR results, a normalization step using stable and constantly expressed genes is crucial $^{6}$. Additionally, the range of impacts of environmental pollutants depends on several factors, including concentration and duration of exposure to chemicals, as well as the stage of development, especially in species with molting systems ${ }^{7}$.

In general, the expression value (Ct) of the target gene was normalized to that of the reference genes, called the housekeeping genes, to compensate for differences among RNA samples ${ }^{8,9}$. Commonly used reference genes contain the $18 S$ rRNA, $\beta$-actin, and GAPDH genes $10,11,12$ in crustaceans (mainly large crustaceans). Few studies have validated reference genes in small crustaceans ${ }^{13,14}$. It has been suggested that the expression of reference genes can be modulated by different environmental stresses ${ }^{15}$, indicating that some housekeeping genes may be involved in pathways other than cellular homeostasis ${ }^{16}$. Thus, reliable reference genes should be selected prior to experiments, and it is recommended that at least two reference genes be employed to avoid incorrect results ${ }^{17,18}$.

In aquatic ecosystems, coastal areas are vulnerable to land pollution due to substances derived from industries, wastewater, farming, and tourism. Many studies have shown that aquatic organisms, whether in situ environments or cultured in the laboratory, can be used to evaluate pollution and to test ecotoxicological responses ${ }^{19,20}$. In particular, brackish water species have a wide range of adaptations to environmental physico-chemical conditions, 
such as salinity and temperature, and are considered suitable for monitoring and risk assessment of various pollutants originating from land and marine environments. The brackish water flea Diaphanosoma celebensis, that belongs to Crustacea, Branchiopoda, and Cladocera, is one of the species of interest to many scientists as potential non-model species for marine pollution $21,22,23$. They are widely distributed in tropical Asia at a wide range of salinity and temperature. In particular, D. celebensis has several advantages such as a short life cycle (45 days), filter-feeders that might be exposed to several pollutants both in water or particles, small body length, and easy culture under laboratory conditions. Most importantly, single-breeding makes genetically identified results in genomic information. This is a great advantage that can be used for transcriptomic research with high efficiency. In fact, in recent studies, the genome and transcriptome of $D$. celebensis were published ${ }^{24,25}$, leading to their potential use at the molecular level in marine ecotoxicology. However, studies on the validation of reference genes are not explored yet in this species.

In this study, we selected nine common housekeeping genes as candidate reference genes from previous studies $^{26,27,28,29}$ and compared their stability in expressions to identify appropriate reference genes under conditions such as chemical exposure and age. For this, three representative chemicals, benzo[a]pyrene (B[a]P), bisphenol A (BPA), and mercury (Hg), were selected. In particular, we focused on their growth ages, as this experimental species has a molting process with different sensitivities to growth ${ }^{30,31}$. Therefore, we investigated the stability of the nine candidate reference genes under different ages (24-h, 4-day, 7-day, and 10-day) and measured the relative expression of target genes based on the conditions of reference genes.

\section{Results}

\section{PCR amplification of nine candidate reference genes.}

Nine common reference genes in D. celebensis, alpha-tubulin (Atb), $\beta$-actin (Act), 18S ribosomal RNA (18S), glyceraldehyde-3-phosphate dehydrogenase $(G A P D H)$, elongation factor 1-beta $(E F-1 b)$, ubiquitin conjugating enzyme $(U B C)$, histone $\mathrm{H} 2 \mathrm{~A}(H 2 A)$, TATA-box binding protein $(T B P)$, and succinate dehydrogenase $(S D H)$ were selected as candidate references for the analysis of gene expression under stress conditions made by three representative chemicals (e.g., BPA, B[a]P, Hg), and different ages (24-h, 4-day, 7-day, and 10-day). The information of all nine candidates, such as their gene IDs, gene, size of the PCR products, Tm values, and the median Ct values, is shown in Table 1. In general, the sizes of the qPCR products of all the tested genes ranged from $81 \mathrm{bp}$ to $108 \mathrm{bp}$. The applicability of the primers designed for the qPCR amplification of these nine candidate genes was verified by RT-PCR and sequencing of the amplified products (Supplementary Information, Text S1). The unimodal melting curves indicate that the primers used in this study have high specificity (Text S1). Furthermore, the efficiency values ranged from $90.8-106.6 \%$ (Table 1). Therefore, our qRT-PCR results were confirmed to be valid and reliable. 
Table 1

Summary of nine reference genes

\begin{tabular}{|c|c|c|c|c|c|c|}
\hline $\begin{array}{l}\text { Gene } \\
\text { symbol }\end{array}$ & $\begin{array}{l}\text { Gene } \\
\text { description }\end{array}$ & $\begin{array}{l}\text { GenBank } \\
\text { accession } \\
\text { no. }\end{array}$ & Primer sequences $\left(5^{\prime}-3^{\prime}\right)$ & $\begin{array}{l}\text { Amplicon } \\
\text { size (bp) }\end{array}$ & $\begin{array}{l}\operatorname{Tm} \\
\left({ }^{\circ} \mathrm{C}\right)\end{array}$ & $\begin{array}{l}\text { Efficiency } \\
\text { (\%) }\end{array}$ \\
\hline \multirow[t]{2}{*}{ Atb } & \multirow[t]{2}{*}{ Alpha-tubulin } & \multirow[t]{2}{*}{ MH636293 } & GCATGATTTCCAACACGAC & \multirow[t]{2}{*}{97} & 55.2 & \multirow[t]{2}{*}{93.92} \\
\hline & & & TACCAGTGAACGAAGGCT & & 53.9 & \\
\hline \multirow[t]{2}{*}{ Act } & \multirow[t]{2}{*}{ beta-actin } & \multirow[t]{2}{*}{ MH636289 } & CAAGATTGTCGCTCCTCCTG & \multirow[t]{2}{*}{84} & 60.5 & \multirow[t]{2}{*}{90.79} \\
\hline & & & CATCTGCTGGAAGGTGG & & 59.5 & \\
\hline \multirow[t]{2}{*}{$18 s$} & \multirow{2}{*}{$\begin{array}{l}\text { 18s ribosomal } \\
R N A\end{array}$} & \multirow[t]{2}{*}{ AF144210.1 } & TGGAAGGATTGACAGATTGA & \multirow[t]{2}{*}{81} & 54.3 & \multirow[t]{2}{*}{101.89} \\
\hline & & & CTTAGTTGGTGGAGCGATTT & & 56.4 & \\
\hline \multirow[t]{2}{*}{ GAPDH } & \multirow{2}{*}{$\begin{array}{l}\text { Glyceraldehyde- } \\
\text { 3-phosphate } \\
\text { dehydrogenase }\end{array}$} & \multirow[t]{2}{*}{ MH636290 } & AACTGTCGCCGCTGTTGA & \multirow[t]{2}{*}{86} & 56.1 & \multirow[t]{2}{*}{96.31} \\
\hline & & & ATGGAATGTTCTTGGGGTCG & & 58.4 & \\
\hline \multirow[t]{2}{*}{$E F-1 b$} & \multirow{2}{*}{$\begin{array}{l}\text { Elongation } \\
\text { factor 1-beta }\end{array}$} & \multirow[t]{2}{*}{ MH636295 } & CGGCTGTGTCGTTGAAGA & \multirow[t]{2}{*}{94} & 56.1 & \multirow[t]{2}{*}{106.67} \\
\hline & & & GGCAATGTCCACACTCTG & & 56.1 & \\
\hline \multirow[t]{2}{*}{$U B C$} & \multirow{2}{*}{$\begin{array}{l}\text { Ubiqutin } \\
\text { Conjugating } \\
\text { enzyme }\end{array}$} & \multirow[t]{2}{*}{ MH636294 } & ССTTTTGACGGACCCATAT & \multirow[t]{2}{*}{104} & 55.2 & \multirow[t]{2}{*}{103.89} \\
\hline & & & TAGTCCAACAGCGAGCAATA & & 56.4 & \\
\hline \multirow[t]{2}{*}{$H 2 A$} & \multirow[t]{2}{*}{ Histone $\mathrm{H} 2 \mathrm{~A}$} & \multirow[t]{2}{*}{ MH636296 } & GAATACCTGGCTGCTGAAG & \multirow[t]{2}{*}{90} & 56.1 & \multirow[t]{2}{*}{101.35} \\
\hline & & & CAATTGGAGATGACGGGG & & 57.3 & \\
\hline \multirow[t]{2}{*}{$T B P$} & TATA-box & MH636292 & TTTCCTGGCTTAATTTACCGTA & 101 & 54.3 & 96.37 \\
\hline & & & ATCTCTTGTCTGACTTTGGC & & 56.4 & \\
\hline$S D H$ & Succinate & MH636291 & CATCGAGTCTCAACAGAAGA & 91 & 56.4 & 100.16 \\
\hline & & & GAGCTCAACCTTTCCAGTT & & 55.2 & \\
\hline
\end{tabular}

\section{Expression level of nine reference genes.}

As shown in the results and box and whisker plots (Tables 2, 3, and Fig. S1), the Ct value distribution of nine reference genes under different conditions varied from 8.7 to 28.3. The $18 \mathrm{~S}$ gene encoded the most abundant transcripts in $D$. celebensis, reaching the threshold fluorescence peak after approximately 10 cycles with the lowest median Ct value (Ct<10, Table 2, Table 3, and Fig.S1) compared to those of other candidate reference genes during qPCR amplification when the same amounts of total RNA (500ng) were used as templates for reverse transcription reactions. The least abundant transcripts were Atb, which had a Ct value of 21 or higher (21.93 \pm 0.38), for chemical treatment. In a test using different ages, UBC had the highest Ct mean values $(25.80 \pm 0.54)$. However, with regard to variations in Ct values, Atb genes showed significant differences between all ages of development (ANOVA, $p<0.05)$. 
Table 2

Cycle threshold (Ct) values of nine putative reference genes in 12 mRNA at different conditions (three chemicals and four concentrations) from a monoculture of Diaphanosoma celebensis exposed to chemicals. (Min., minimum; Max., maximum; SD, standard deviation; SE, standard error; CV, coefficient of variation.)

\begin{tabular}{|llllllll|}
\hline Gene & \multicolumn{6}{l}{ Ct value statistics } \\
\cline { 2 - 8 } & min & $\max$ & max-min & mean & SD & SE & CV \\
\hline Atb & 21.18 & 22.48 & 1.30 & 21.93 & 0.38 & 0.06 & 0.02 \\
\hline Act & 16.06 & 16.52 & 0.46 & 16.26 & 0.09 & 0.01 & 0.01 \\
\hline TSS & 8.70 & 9.61 & 0.91 & 9.19 & 0.21 & 0.03 & 0.02 \\
\hline GAPDH & 17.00 & 18.27 & 1.27 & 17.32 & 0.23 & 0.03 & 0.01 \\
\hline EF-1b & 17.34 & 18.39 & 1.05 & 17.80 & 0.20 & 0.03 & 0.01 \\
\hline UBC & 21.40 & 22.23 & 0.83 & 21.82 & 0.20 & 0.03 & 0.01 \\
\hline H2A & 18.26 & 18.98 & 0.72 & 18.49 & 0.17 & 0.02 & 0.01 \\
\hline TBP & 20.85 & 21.65 & 0.8 & 21.21 & 0.20 & 0.03 & 0.01 \\
\hline SDH & 18.60 & 19.54 & 0.94 & 19.00 & 0.19 & 0.03 & 0.01 \\
\hline
\end{tabular}

Table 3

Cycle threshold (Ct) values of nine putative reference genes in 12 mRNA samples from a monoculture of Diaphanosoma celebensis at different ages (Min., minimum; Max., maximum; SD, standard deviation; SE, standard error; $\mathrm{CV}$, coefficient of variation.)

\begin{tabular}{|llllllll|}
\hline \multirow{2}{*}{ Gene } & \multicolumn{6}{l}{ Ct value statistics } \\
\cline { 2 - 8 } & min & $\max$ & $\max -\min$ & mean & SD & SE & CV \\
\hline Atb & 18.85 & 28.27 & 9.42 & 23.82 & 3.41 & 0.57 & 0.14 \\
Act & 18.97 & 21.29 & 2.32 & 19.75 & 0.57 & 0.10 & 0.03 \\
\hline I8S & 9.59 & 13.43 & 3.84 & 11.18 & 1.14 & 0.19 & 0.10 \\
\hline GAPDH & 19.41 & 21.79 & 2.38 & 20.31 & 0.63 & 0.11 & 0.03 \\
EF-1b & 21.51 & 24.23 & 2.72 & 22.20 & 0.69 & 0.12 & 0.03 \\
\hline UBC & 24.99 & 26.80 & 1.81 & 25.80 & 0.54 & 0.09 & 0.02 \\
\hline$H 2 A$ & 22.22 & 23.86 & 1.64 & 22.88 & 0.45 & 0.08 & 0.02 \\
\hline TBP & 24.21 & 26.85 & 2.64 & 25.39 & 0.90 & 0.15 & 0.04 \\
\hline$S D H$ & 22.00 & 24.12 & 2.12 & 22.90 & 0.46 & 0.08 & 0.02 \\
\hline
\end{tabular}




\section{The stability of candidate reference genes under chemical exposures.}

The stability of the reference genes showed different results according to the chemicals (Fig. 1, Fig. S2-S5). Based on the $M$ values evaluated by geNorm, all genes and chemicals showed $M$ values of less than 1 , an acceptable value considering suitable reference genes for RT-qPCR normalization in all chemical exposure conditions (Fig. 1, Fig. S2). Act and GAPDH were the best reference genes for samples exposed to B[a]P (Fig. S2A) and BPA (Fig. $\mathrm{S} 2 \mathrm{~B}$ ). Upon exposure to $\mathrm{Hg}, U B C$ and $T B P$ were the most suitable reference genes (Fig. S2C). When considering all samples exposed to three different chemicals, the $M$ values of all genes were stable in the following order: $H 2 A$, EF-1b, UBC, TBP, Act, 18S, SDH, GAPDH, and Atb (Fig. 1).

NormFinder also showed different results depending on the sample group exposed to the chemical (Fig. S3). Act, Atb, and TBP were the most stable genes for exposure to B[a]P, BPA, and Hg, respectively (Fig. S3A-S3C). The results calculated by NormFinder were somewhat similar to those from geNorm in some representative genes in stability order for each chemical and whole samples (Fig. 1B).

For all cases, including each chemical and all samples, Act was the most stable reference gene in BestKeeper (Fig. 1C and Fig. S4). This method showed similar ranking results to other methods, but the order was observed to be different for $\mathrm{Hg}$ exposure (Fig S4C). Upon exposure to $\mathrm{Hg}$, other methods (geNorm and NormFinder) showed that TBP and UBC were suitable, but only the BestKeeper showed $A c t$ and $H 2 A$ as suitable candidates. This result is also the same in the case where all samples were gathered.

RefFinder, a web-based analysis tool, integrates three major computational programs, geNorm, NormFinder, and BestKeeper, and the comparative $\Delta C$ method to comprehensively rank the tested candidate genes. This comprehensive method summarizes $\mathrm{H} 2 \mathrm{~A}$ and Act as potential reference genes for the chemical treatment of this species (Fig. 1D and Fig. S5).

Interestingly, in BPA exposure, Atb, which showed the most unstable results for the entire sample, was calculated as a stable reference gene as the first (NormFinder) or top ranking in several methods (third stable gene for BestKeeper, second stable gene for RefFinder) only for BPA exposure (Fig. S2-S5). When all three chemicals are considered together, either at the commonly used thresholds (1.5 for M-value for geNorm, SD lower than 1 for BestKeeper) or stability order (RefFinder), $H 2 A$ and Act have similarly high stability.

\section{The stability of candidate reference genes under biotic conditions: Different ages}

Each age group ( $24 \mathrm{~h}, 4 \mathrm{~d}, 7 \mathrm{~d}$ and $10 \mathrm{~d}$ post hatching) showed different stabilities for the nine reference genes of the brackish water flea D. celebensis (Fig. 2, Fig. S6-9). Interestingly, individuals at post-24h showed TBP to be the most unstable, whereas this gene was relatively stable at other ages of growth (days 4, 7, and 10). Even on day 4 , the TBP gene was found to be the most stable in the NormFinder method (Fig. S7). All results showed that Atb was the most unstable, except at $24 \mathrm{~h}$ (Fig. 2 and Fig. S6-S9). In particular, the stability of Atb gene expression on day 4 was significantly different from that of the other genes. For example, in geNorm, only Atb had an $\mathrm{M}$ value greater than 1, and the next unstable gene, 18S, was 0.5 . 
NormFinder and BestKeeper also showed that Atb was the most unstable gene, and also showed a large difference in stability value with the next unstable genes, SDH and 18S, respectively (Fig. 2 and Fig S6-S8). NormFinder showed different results from geNorm in the order of stability order: GAPDH, EF-1b, Act, 18S, H2A, SDH, $U B C, T B P$, and $A t b$, while the three most stable genes were the same. BestKeeper showed that $S D H$ is the most stable gene when considering all age samples. The stable results of $18 S$ shown in geNorm and NormFinder do not apply to the seven-day individuals as coefficients in BestKeeper of 18 S over 1, the threshold of this algorithm. Finally, the integrated approach RefFinder indicates that Act is the most stable gene for covering all ages of $D$. celebensis (Fig. S8).

\section{Impact of reference genes on real-time qRT-PCR data analysis of target genes.}

To validate the selected reference genes using algorithms, the expression of target genes was normalized and compared at different conditions. First, the pairwise variation ( $V$ ) suggested that two reference genes are required for the normalization of gene expression levels (Fig. 3). In fact, all V values evaluated by geNorm were less than 0.15 , which is the criterion for selecting a suitable reference gene number for the normalization of gene expression in chemical treatments. However, a test conducted using individuals of different ages showed that increasing the number of reference genes did not always increase reliability (Fig. 3B). For differential ages, Act and GAPDH were selected using RefFinder as stable reference genes.

The expression levels of GSTmu were compared between the most stable and unstable genes; however, no difference was found in the levels and patterns regardless of stable $(H 2 A)$ or not (Atb) (Fig. 4). However, studies performed using $D$. celebenesis of different ages showed significantly different expression patterns of GSTsigma and EcRA depending on which reference gene was used for normalization (Fig. 5 and Fig. S10). In particular, the result using $A t b$ as a reference gene showed superficially different expression patterns of target genes (highly expressed GSTsigma and ECRA at day 4) unlike other cases using stable reference genes (GAPDH, Act, and both genes).

\section{Discussion}

With its rapid development, qRT-PCR has been widely used to evaluate the expression of target genes in recent years $^{32}$. In particular, gene expressions in organisms collected in environments sometimes provide integrated information to assess environmental stress conditions without restricting the number of samples, times, and repeatability ${ }^{33}$. Recently, RNA transcriptomics has become an irreplaceable approach to measure the expression of the target gene in many fields based on biology in the rapid extraction of large-scale biological samples; however, these advantages, such as fast and mass processing, can cause inevitable errors. Thus, the so-called "housekeeping" genes as internal references have been attracting attention for several years and in all major organisms. Briefly, the absolute expression level of the target gene was calibrated based on that of the reference gene. This indicates that reliable validation of the reference gene is a pivotal step in the use of gene expression for further discussion using qRT-PCR. Furthermore, recent studies have reported that various physiological responses are affected by xenobiotic stress, including persistent organic pollutants and heavy metals ${ }^{34,35}$. The expression of specific genes associated with these physiological alterations shows biological repercussions and the status of 
the environment. This is the reason why the comprehensive evaluation of reference gene stability in response to diverse biotic and abiotic factors is a rising issue.

However, no reference gene is truly stably expressed for any type of stress, although many studies are being conducted ${ }^{36}$. Differential expression of the internal gene under different experimental conditions or at different developmental stages causes errors in normalization of relative expression levels. Furthermore, the variability of the reference gene has been easily overlooked as an advantage of gene expression studies using this approach. This means that the use of a reference gene for calculating the expression of target genes under specific conditions is always required when new species are used in ecotoxicological studies ${ }^{14}$.

Reference gene validation has been performed in many other aquatic invertebrates, such as cladocera Daphnia magna ${ }^{13}$, amphipod Gammarus fossarum ${ }^{14}$, and bivalves Pecten maximus L. $^{37}$ and Ruditapes philippinarum ${ }^{38}$. In particular, Volland et al. ${ }^{38}$ demonstrated that many unvalidated uses of genes still introduce artefactual variance, causing misinterpretations of gene expression. These studies insist that preliminary investigations, such as conducting basic research to find reference genes, are important for studies using gene expression as well as for toxicogenomics. Furthermore, the results of studies on reference genes have been helpful in using these species in ecotoxicological studies, followed by the suggestion of specific genes ${ }^{39,40}$. In the brackish water flea, $D$. celebensis is also one of the potential species that might be used in several studies on pollution in many tropical and coastal areas, either in lab-based work or fields $25,41,42$. The nine candidate reference genes, Atb, Act, 18S, $G A P D H, E F-1 b, U B C, H 2 A, T B P$, and $S D H$ were used to identify adequate and reliable reference genes for brackish water flea exposed to waterborne chemicals. In our study, however, no reference gene was excluded from analysis because all primer pairs yielded sufficient efficiencies in RT-qPCR (Ct values $<30$ ).

In the four different approaches for stability testing, each method selected the stability of the potential reference genes with different orders (Table S1). When considering all samples for the three chemical exposures, NormFinder showed different results in the order $(H 2 A, A c t, E F-1 b, 18 S)$ of stability compared to those collected by geNorm ( $H 2 A, E F-1 b$, and TBP). Many studies insist that these two methods yield similar results, but the discrepancy between geNorm and NormFinder in this study might be explained by the high expression shown in 18S (approximately two-fold Ct value smaller than any other gene). The BestKeeper, which indicates the standard deviation (SD) of $\mathrm{Ct}$ is considered stable when a value less than 1 leads to similar results from NormFinder for the two most stable genes.

To validate the effect of the reference gene, we compared the target genes under different conditions of the reference gene. GST, selected as a target gene, is a phase II detoxifying enzyme that involves the removal of electrophilic substances using reduced glutathione (GSH) as a substrate in most organisms ${ }^{43}$. In particular, it is well established as a biomarker for diagnosis of pollution as GST mediates the binding between reactive metabolites generated by phase I enzymes and the thiol group of GSH, thereby converting it to a nontoxic form ${ }^{44}$. Our recent study also showed that the GST isoform, particularly GSTmu of D. celebensis normalized by $18 S$ rRNA, was similarly upregulated in the presence of heavy metals and BPA exposure ${ }^{46,47}$. The increased patterns of GSTmu observed in the chemical exposures demonstrated that the calculated results based on reference genes in this study are reasonable. Furthermore, the results in which chemical exposures did not elicit comparable patterns in target genes suggested that all reference genes could be candidates when using individuals at least by day 4 of these three chemical exposures (Fig. 4). These results were expected, as all genes used in this batch had $M$ values at geNorm significantly lower than the cut-off, 1.5 (Fig. 1A). 
On the other hand, the different ages cause differential expression of reference genes, even though these nine genes are believed to be suitable for reference and showed stable results in other studies, including our first batch of experiments conducted under chemical exposure $26,27,28,29$. First, the alterations of GSTsigma at different ages suggested that age may have different abilities to metabolize, resulting in different gene expressions. In $D$. celebensis, 4-day old release the first brood of neonates ${ }^{21}$ and 7-day old are in the molting period (unpublished data). This indicates that different age groups may lead to large alterations in the expression of some reference genes. As expected, the result calculated from the use of an unstable reference $(A t b)$ causes a distinct pattern of GSTsigma, as if the 4-day individuals were overestimated.

The expression patterns of another selected target gene, ecdysteroid receptor $\mathrm{A}(E c R A)$, was also similar to GSTsigma. EcRA is a key marker that is involved in the transport of ecdysteroid, a molting hormone in arthropods, into the nucleus, and thus plays a key role in the modulation of growth, reproduction, and development ${ }^{48}$. Differently modulated expression according to age with the molting process suggested that these genes can be markers of $D$. celebensis to evaluate development ${ }^{22}$. However, the selection of $A t b$ resulted in significantly different results in target gene expression. This indicates that the $\mathrm{Ct}$ value of $A t b$ highly fluctuates according to age. This can be a falsification to report that $A t b$ levels remain stable and good candidates as a reference gene for this organism as day 4 is the tipping point of life table for the growth of $D$. celebensis. In the case of both GAPDHand $A c t$, there was no difference in the expression level in each group, but the expression level of target genes was significantly upregulated in a normalization with $A t b$ (t-test, $p<0.05)$. Previous studies have also pointed out that

some reference genes can be differently suggested according to the developmental stage of the plant ${ }^{49,50}$. Thus, the results obtained from $D$. celebensis show evidence of the importance of reference gene selection to avoid misinterpretation in specific organisms that have distinctive growth and reproductive periods in life tables.

\section{Conclusion}

In our study, nine candidate reference genes were selected for real-time qRT-PCR standardization and evaluated using four different algorithms. The different analytical methods result in comparable values and ranks of the candidates, but the integrated application of these results leads to more reliable information on which gene must be sorted out. The results showed that $\mathrm{H} 2 \mathrm{~A}$ and $\mathrm{Act}$ were the most stable reference genes for considering 4th day individuals of brackish water flea for chemical exposure, while Atb was the most unstable reference gene.

The results for the unstable gene were the same in terms of age. However, the selection of the reference gene results in a significantly different pattern in the target gene when prominent development or alterations, such as molting or reproduction, are observed. This is of great importance in marine environments, as most hypotrophic organisms have a short life cycle, rapid sexual maturation, and prominent features such as idiosyncratic growth, such as molting.

The stable reference genes identified in this study will enhance the accuracy of qRT-PCR-based analysis of target gene expression and can be used to study related ecotoxicological applications using this species in estuarine environments. In this study, normalization with the most stable or with a combination of two carefully chosen reference genes led to different patterns in the expressions that were calculated using unsuitable reference genes. Thus, careful evaluation of the reference genes prior to expression studies is essential. For future directions in environmental studies, more studies are required as the selection of appropriate reference genes from field 
conditions might be more complex than controlled environmental studies. However, the results accumulated in many studies will be useful for extracting candidates for future studies.

\section{Materials And Methods Reagents.}

All chemical reagents used in this study were of ultrapure grade for molecular biology and purchased from SigmaAldrich Co. (Saint Louis, MO, USA), unless otherwise mentioned. All oligonucleotide synthesis and DNA sequencing analyses were performed using Bionics (Seoul, South Korea).

\section{Culture and maintenance.}

The cladoceran D. celebensis strain was maintained at the Molecular Toxicology Laboratory of Sangmyung University, South Korea, since they were obtained from Dr. Kyun-Woo Lee of the Korea Institute of Ocean Science \& Technology (KIOST; Busan, South Korea) in 2015. The culture medium used was $0.2 \mu \mathrm{m}$-filtered artificial seawater (15 psu) using Instant Ocean (Aquarium system, France). Culture conditions were maintained at a photoperiod of $12 \mathrm{~h}: 12 \mathrm{~h}$ light/dark and $25 \pm 1^{\circ} \mathrm{C}$. The food source was Chlorella vulgaris $\left(4 \times 10^{7} \mathrm{cells} / \mathrm{L}\right)$ cultured in Jaworski's medium and supplied once every two days.

\section{Waterborne exposure to chemicals.}

Three chemicals (BPA, B[a]P, and $\mathrm{Hg}$ ), which have been extensively studied in aquatic environments, were selected as representative toxicants. Stock solutions of BPA (2,2,-bis-(4-hydroxyphenyl) propane; 3 mg/ml), B[a]P (5 mg/ml) were prepared by dissolving in dimethyl sulfoxide (DMSO), and those of $\mathrm{Hg}\left(\mathrm{HgCl}_{2}\right)$ were dissolved in distilled water at a concentration of $1 \mathrm{mg} / \mathrm{ml}$. Working solutions were prepared by adding stock solution to $200 \mathrm{ml}$ of 15 psu sea water. To examine the concentration-dependent effects of chemicals, D. celebensis (4 days old, 200 individuals/each concentration) was exposed to BPA $(1.5,3$, and $6 \mathrm{mg} / \mathrm{L}), \mathrm{B}[\mathrm{a}] \mathrm{P}(0.3,0.6$ and $1.2 \mathrm{mg} / \mathrm{L})$, and $\mathrm{Hg}$ $(2.5,5$, and $10 \mu \mathrm{g} / \mathrm{L})$ for $48 \mathrm{~h}$ in a $250 \mathrm{ml}$ beaker. The concentrations of each chemical were designed based on an acute toxicity test that was conducted as a preliminary study (Table S2). In addition, to check the developmental stage-dependent effects, 24 h, 4 d, 7 d, and 10 d old D. celebensis ( 200 individuals/each concentration) were used. The final DMSO concentration was less than $0.05 \%$, and no mortality was observed. All examinations were performed in triplicates.

\section{Total RNA extraction and cDNA synthesis.}

D. celebensis was collected $48 \mathrm{~h}$ after exposure to chemicals or at different developmental stages and homogenized in five volumes of TRIzol reagent (Thermo Fisher Scientific Inc., USA). Total RNA was extracted according to the manufacturer's instructions and kept at $-80^{\circ} \mathrm{C}$ until use. The quality and quantity of total RNA were checked using agarose gel electrophoresis and a Nano drop (Maestrogen Nano Drop, Taiwan). cDNA was synthesized from 500 ng of total RNA using the RevertAid First Strand cDNA Synthesis Kit (Thermo Fisher Scientific Inc., USA). 


\section{Polymerase chain reaction (PCR) amplification and sequence analysis.}

The cDNA sequences of nine reference genes ( $A t b, A c t, 18 S, G A P D H, E F-1 b, U B C, H 2 A, T B P$, and $S D H$ ) were obtained from the local database of $D$. celebensis transcriptome (Molecular Toxicology Laboratory, Sangmyung University). The PCR protocol was as follows: $95^{\circ} \mathrm{C}$ for $2 \mathrm{~min} ; 35$ cycles of $95^{\circ} \mathrm{C}$ for $30 \mathrm{~s}, 55^{\circ} \mathrm{C}$ for $30 \mathrm{~s}, 72^{\circ} \mathrm{C}$ for 2 min; and an extension step at $72^{\circ} \mathrm{C}$ for $10 \mathrm{~min}$. The PCR product was visualized on a $1.4 \%$ agarose gel and purified using the AccuPrep ${ }^{\circledR}$ Gel Purification Kit (Bioneer, South Korea) for sequencing. Basic Local Alignment Search Tool (BLAST) homology searches of databases were performed using Blast + 2.8.1 from the NCBI to identify the gene. The sequences of each gene were deposited in GenBank (Table 1).

\section{Quantitative real-time RT-PCR.}

To validate the reference genes, real-time qRT-PCR was performed using a CFX96 $6^{\text {TM }}$ real-time PCR system (Bio-Rad, USA). Each PCR reaction involved $2 \mu \mathrm{l}$ CDNA and $2 \mu \mathrm{l}$ of $10 \mathrm{pmol}$ primer set (Table 1). The PCR cycle conditions were as follows: $95^{\circ} \mathrm{C}$ for $10 \mathrm{~min}$, followed by 33 cycles of $95^{\circ} \mathrm{C}$ for $15 \mathrm{~s}, 60^{\circ} \mathrm{C}$ for $1 \mathrm{~min}$. To check a specific product after PCR, melting curves were analyzed under the following conditions: $95^{\circ} \mathrm{C}$ for $15 \mathrm{~s}$ and $60^{\circ} \mathrm{C}$ for $1 \mathrm{~min}$ with a $0.5^{\circ} \mathrm{C}$ increase per second (Text S1). All experiments used SYBR master mix (KAPA Bioassay System, USA) and performed in triplicate. The threshold cycle $(\mathrm{Ct})$ from each experiment was used to compare the stability of the reference genes. All examinations were performed in triplicates.

\section{Expression stability analysis of candidate reference genes.}

The Ct values obtained from qRT-PCR were analyzed using geNorm (Vandesompele et al. 2002), NormFinder ${ }^{52}$, BestKeeper ${ }^{53}$, and RefFinder (https://www.heartcure.com.au/reffinder/) algorithms. For geNorm, the expression stability of nine reference genes was evaluated using statistical analysis and the average expression stability (M value) using geNorm analysis ${ }^{51}$ in qbase PLUS 3.2 (Biogazelle, Ghent, Belgium). Similar to geNorm, NormFinder also calculated the average expression stability values based on the $2^{-\Delta \mathrm{Ct}}$ value, and low values were stable. BestKeeper, a method using the Ct value directly without any conversion step, showed stability based on the coefficient of variance (CV) and standard deviation (SD), and RefFinder integrating all the results from the three software mentioned above, was used to calculate the ranking index for showing stability in this study. In addition, the optimal number of reference genes required for reliable normalization was also evaluated by pairwise variation ( $V$ value) through geNorm analysis ${ }^{51}$.

\section{Normalization with reference genes.}

From the stability analysis, the less stable and the most stable reference genes were used to normalize the expression of one target gene (glutathione S-transferase $\mathrm{mu}, \mathrm{gst}-\mathrm{mu}$ ) in 4-day old $\mathrm{D}$. celebensis exposed to chemicals for $48 \mathrm{~h}$. On the other hand, one less stable and two more stable reference genes were used to normalize the expression of two target genes (ecdysone receptor A, EcRA; glutathione S-transferase, GST-sigma, and GST-mu) in D. celebensis of four different ages. These genes were selected as target genes because they 
showed the most significant changes under chemical exposure conditions in our previous studies $42,45,46,47$. The fold change values were calculated using the $2^{\triangle \triangle \mathrm{Ct}}$ method ${ }^{54,55}$ using formulas (1) and (2):

\section{Average $C T$ of reference genes $(R G): C T_{R G}=\left(C T_{R G 1}+C T_{R G 2}+\ldots+C T_{R G n}\right) /$ $\mathrm{n}(1)$}

\section{Gene expression level: $\mathrm{G}=2^{-}$(CTgene - CTRG) $(2)$ Statistical analysis.}

Data from all experiments are represented as the mean \pm standard deviation (SD) of the three replicates. One-way analysis of variance (one-way ANOVA) and Student's t-test followed by Tukey's test were used for statistical analysis among samples using the PASW statistics 18.0 program (SPSS Inc., Chicago, IL, USA). Statistical significance was set at $p<0.05$.

\section{Declarations}

\section{Acknowledgement}

This study was funded by the National Research Foundation of Korea (2020R1F1A1069736) to Young-mi Lee and also supported by the National Research Foundation of Korea (2021R1C1C2005922) to Eun-Ji Won.

\section{Author contributions}

Y.-M.L., Conceptualization, writing, editing, funding; R.-O.K., experiments, analysis; H.Y.C. and S.I., experiments, imaging, statistical analysis; S.-J.K., data analysis; E.-J.W., Conceptualization, writing, editing, funding. All authors have read and agreed to the published version of the manuscript.

\section{Competing interests}

The authors declare no competing interests.

\section{References}

1. Chouvelon, T. et al. Chemical contaminants (trace metals, persistent organic pollutants) in albacore tuna from western Indian and south-eastern Atlantic Oceans: Trophic influence and potential as tracers of populations. Sci. Total Environ, 596-597, 481-495 (2017).

2. Ali, H., Khan, E. \& Ilahi, I. Environmental Chemistry and Ecotoxicology of Hazardous Heavy Metals: Environmental Persistence, Toxicity, and Bioaccumulation.J. Chem. Article ID6730305. (2019).

3. Leppänen, J. J. An overview of Cladoceran studies conducted in mine water impacted lakes. Int. Aquat. Res, 10, 207-221 (2018). 
4. Nolan, T., Hands, R. E. \& Bustin, S. A.Quantification of mRNA using real-time RT-PCR. Nat.Protoc, 1, 15591582 https://doi.org/10.1038/nprot.2006.236 (2006).

5. Valones, M. A. et al. Principles and applications of polymerase chain reaction in medical diagnostic fields: a review. Braz. J. Microbiol, 40, 1-11 (2009).

6. Dheda, K. et al. Validation of housekeeping genes for normalizing RNA expression in real-time PCR., 37, 112119 (2004).

7. Chendler, G. T. \& Green, A. S. Developmental stage-specific life-cycle bioassay for assessment of sedimentassociated toxicant effects on benthic copepod production. Environ. Toxicol. Chem, 20, 171-180 (2001).

8. Martins, P., Mafra, V. \& de Souza, W. Selection of reliable reference genes for RT-qPCR analysis during developmental stages and abiotic stress in Setaria viridis. Sci. Rep, 6, 28348 (2016).

9. Luo, X. et al. Stable reference gene selection for RT-qPCR analysis in Synechococcus elogatus PCC 7942 under abiotic stresses. Biomed Res. Int, 3, 1-15 (2019).

10. Cottin, D. et al. Comparison of heat-shock responses between the hydrothermal vent shrimp Rimicaris exoculata and the related coastal shrimp Palaemonetes varians. J. Exp. Mar. Biol. Ecol, 393, 9-16 (2010).

11. Leelatanawit, R., Klanchui, A., Uawisetwathana, U. \& Karoonuthaisiri, N. Validation of reference genes for realtime PCR of reproductive system in the black tiger shrimp. PloS one, 7(12), e52677(2012)

12. Jaramillo, M. L. et al. Identification and evaluation of reference genes for expression studies by RT-qPCR during embryonic development of the emerging model organism. Macrobrachium olfersii, Gene, 598, 97-106 (2017).

13. Heckmann, L. H. et al. Expression of target and reference genes in Daphnia magna exposed to ibuprofen. BMC Genomics, 7, 175 (2006).

14. Mehennaoui, K. et al. Identification of reference genes for RT-qPCR data normalization in Gammarus fossarum (Crustacea Amphipoda). Sci. Rep, 8, 15225 (2018).

15. Suzuki, T., Higgins, P. J. \& Crawford, D. R. Control selection for RNA quantitation., 29, 332-337 (2000).

16. Köhsler, M., Leitsch, D., Müller, N. \& Walochnik, J. Validation of reference genes for the normalization of RTqPCR gene expression in Acanthamoeba spp. Sci. Rep, 10, 10362 (2020).

17. Bustin, S. A. et al. The MIQE guidelines: minimum information for publication of quantitative real-time PCR experiments. Clin. Chem, 55, 611-622 (2009).

18. Nicot, N., Hausman, J. F., Hoffmann, L. \& Evers, D. Housekeeping gene selection for real-time RT-PCR normalization in potato during biotic and abiotic stress. J. Exp. Bot, 56, 2907-2914 (2005).

19. Sarma, S. S. \& Nandini, S. Review of recent ecotoxicological studies on cladocerans. J. Environ. Sci. Health B, 41, 1417-1430 (2006).

20. Kwok, W. H. K. P., Souissi, S., Dur, G., Won, E. J. \& Lee, J. S. Copepods as References Species in Estuarine and Marine Waters. In Aquatic Ecotoxicology: Advancing Tools for Dealing with Emerging Risks (pp. 281308).Elsevier Inc. https://doi.org/10.1016/B978-0-12-800949-9.00012-7 (2015)

21. Marcial, H. S. \& Hagiwara, A. Multigenerational effects of $17 \beta$-estradiol and nonylphenol on euryhaline cladoceran Diaphanosoma celebensis. Fish. Sci, 73, 324-330 (2007).

22. In, S. et al. Acute toxicity of bisphenol A and its structural analogues and transcriptional modulation of the ecdysone-mediated pathway in the brackish water flea Diaphanosoma celebensis. Ecotox. Environ. Safe, 179, 310-317 (2019). 
23. In, S., Cho, H., Lee, K. W., Won, E. J. \& Lee, Y. M. Cloning and molecular characterization of estrogen-related receptor (ERR) and vitellogenin genes in the brackish water flea Diaphanosoma celebensis exposed to bisphenol A and its structural analogues. Mar.Pollut. Bull, 154, 111063 (2020).

24. Kim, B. M. et al. De novo transcriptome assembly of brackish water flea Diaphanosoma celebensis based on short-term cadmium and benzo[a]pyrene exposure experiments. Hereditas 155, Article number 36(2018).

25. Kim, D. H. et al. The genome of the marine water flea Diaphanosoma celebensis: Identification of phase I, II, and III detoxification genes and potential applications in marine molecular ecotoxicology. Comp. Biochem. Physiol. D, 37, 100787 (2021).

26. Barber, R. D., Harmer, D. W., Coleman, R. A. \& Clark, B. J. GAPDH as a housekeeping gene: analysis of GAPDH mRNA expression in a panel of 72 human tissues. Physiol. Genomics, 21, 389-395 (2015).

27. Kuchipudi, S. V. et al. 18S rRNA is a reliable normalisation gene for real time PCR based on influenza virus infected cells. Virol. J, 9, 230 (2012).

28. McCulloch, R. S., Ashwell, M. S. \& O'Nan, A. T. Identification of stable normalization genes for quantitative realtime PCR in porcine articular cartilage. J. Anim. Sci. Biotechnol, 3, 36 (2012).

29. Zhang, G. et al. Characterization of reference genes for quantitative real-time PCR analysis in various tissues of Anoectochilus roxburghii. Mol. Biol. Rep, 39, 5905-5912 (2012).

30. Soetaert, A. et al. Daphnia magna and ecotoxicogenomics: gene expression profiles of the anti-ecdysteroidal fungicide fenarimol using energy-, molting- and life stage-related cDNA libraries., 67 (1), 60-71 (2007).

31. Hwang, D. S. et al. BDE-47 causes developmental retardation with down-regulated expression profiles of ecdysteroid signaling pathway-involved nuclear receptor (NR) genes in the copepod Tigriopus japonicus. Aquat. Toxicol, 177, 285-294 (2016).

32. Deepak, S. A. et al. Real-time PCR: Revolutionizing detection and expression analysis of genes. Curr. Genomics, 8, 234-251 (2007).

33. VanGuilder, H. D., Vrana, K. E. \& Freeman, W. M. Twenty-five years of quantitative PCR for gene expression analysis. BioTechniques, 44, 619-626 (2008).

34. Canesi, L. \& Fabbri, E. Environmental effects of BPA: Focus on aquatic species. Dose Response, 13, 1-14 (2015).

35. Hudspith, M., Reichelt-Brushett, A. \& Harrison, P. L. Factors affecting the toxicity of trace metals to fertilization success in broadcast spawning marine invertebrates: A review. Aquat. Toxicol, 184, 1-13 (2017).

36. Czechowski, T., Stitt, M., Altmann, T., Udvardi, M. K. \& Scheible, W. R. Genome-wide identification and testing of superior reference genes for transcript normalization in Arabidopsis. Plant Physiol, 139 (1), 5-17 (2005).

37. Mauriz, O., Maneiro, V., Pérez-Parallé, M. L., Sanchez, J. L. \& Pazos, A. J. Selection of reference genes for quantitative RT-PCR studies on the gonad of the bivalve mollusc Pecten maximus L., 370-371, 158-165 (2012).

38. Volland, M., Blasco, J. \& Hampel, M. Validation of reference genes for RT-qPCR in marine bivalve ecotoxicology: Systematic review and case study using copper treated primary Ruditapes philippinarum hemocytes. Aquat. Toxicol, 185, 86-94 (2018).

39. Solberg, M. F., Kvamme, B. O., Nilsen, F. \& Glover, K. A. Effects of environmental stress on mRNA expression levels of seven genes related to oxidative stress and growth in Atlantic salmon Salmo salar L. of farmed, hybrid and wild origin. BMC Res. Notes, 5, 672 (2012). 
40. Ventoso, P. et al. Transcriptional response in the digestive gland of the King Scallop (Pecten maximus) after the injection of domoic acid. Toxins, 13, 339 (2021).

41. Isabel, L. et al. In situ assays with tropical cladocerans to evaluate edge-of-field pesticide runoff toxicity., 67, 2250-2256 (2007).

42. Yoo, J. et al. Effects of polystyrene in the brackish water flea Diaphanosoma celebensis: Size-dependent acute toxicity, ingestion, egestion, and antioxidant response. Aquat. Toxicol, 235, 105821 (2021).

43. Sheehan, D., Meade, G., Foley, V. M. \& Dowd, C. A. Structure, function and evolution of glutathione transferases: implications for classification of non-mammalian members of an ancient enzyme superfamily. Biochem. J, 360, 1-16 (2001).

44. Regoli, F. \& Giuliani, M. E. Oxidative pathways of chemical toxicity and oxidative stress biomarkers in marine organisms. Mar. Environ. Res, 93, 106-117 (2014).

45. Bae, C. \& Lee, Y. M. Antioxidant responses in brackish water flea Diaphanosoma celebensis-exposed to mercury. J. Mar. Life Sci, 3 (2), 74-80 (2018).

46. Yoo, J., Cho, H. \& Lee, Y. M. Modulation of glutathione S-tranferase and superoxide dismutase in response to heavy metals in brackish water flea Diaphonosoma celebensis. J. Toxicol. Environ, 12, 83-90 (2020).

47. Yoo, J., Cha, J., Kim, H., Pyo, J. \& Lee, Y. M. Modulation of antioxidant defense system in the brackish water flea Diaphanosoma celebensis exposed to bisphenol A. Korean J. Environ. Biol, 37, 72-81 (2019).

48. Nakagawa, Y. \& Henrich, V. C. Arthropod nuclear receptors and their role in molting. FEBS J, 276, 6128-6157 (2009).

49. Wan, Q. et al. Stability evaluation of reference genes for gene expression analysis by RT-qPCR in soybean under different conditions. PLOS ONE, 12 (12), e0189405 (2017).

50. Wang, Y., Zhang, Y. \& Liu, Q. Selection and validation of appropriate reference genes for RT-qPCR analysis of flowering stages and different genotypes of Iris germanica L. Sci. Rep, 11, 9901 (2021).

51. Vandesompele, J., De Preter, K. \& Pattyn, F. Accurate normalization of real-time quantitative RT-PCR data by geometric averaging of multiple internal control genes. Genome Biol, 3, 00341 (2002).

52. Andersen, C. L., Jensen, J. L. \& Orntoft, T. F. Normalization of real-time quantitative reverse transcription-PCR data: a model-based variance estimation approach to identify genes suited for normalization, applied to bladder and colon cancer data sets. Cancer Res, 64, 5245-5250 (2004).

53. Pfaffl, M. W., Tichopad, A., Prgomet, C. \& Neuvians, T. P. Determination of stable housekeeping genes, differentially regulated target genes and sample integrity: BestKeeper-Excel-based tool using pair-wise correlations. Biotechnol. Lett, 26, 509-515 (2004).

54. Livak, K. J. \& Schmittgen, T. D. Analysis of relative gene expression data using real-time quantitative PCR and the 2-DD CT-method., 25, 402-408 (2001).

55. Riedel, G. et al. An extended $\Delta$ CT-Method facilitating normalisation with multiple reference genes suited for quantitative RT-PCR analyses of human hepatocyte-like cells. PLOS ONE, 9 (3), e93031 (2014).

\section{Figures}


Figure 1

(A)

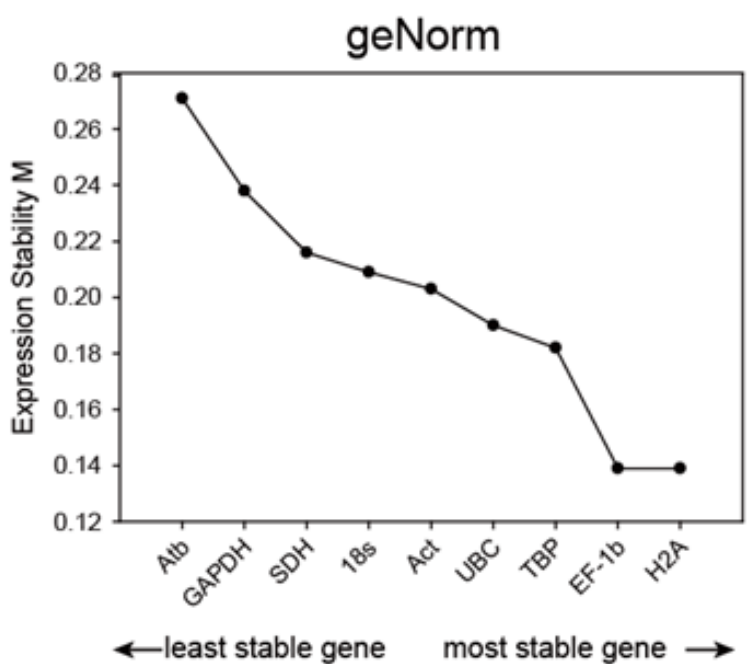

(C)

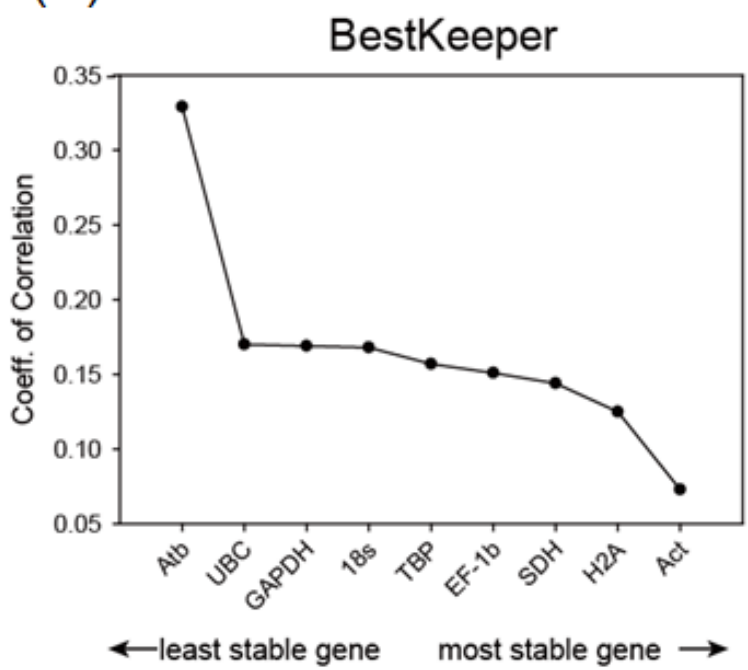

(B)

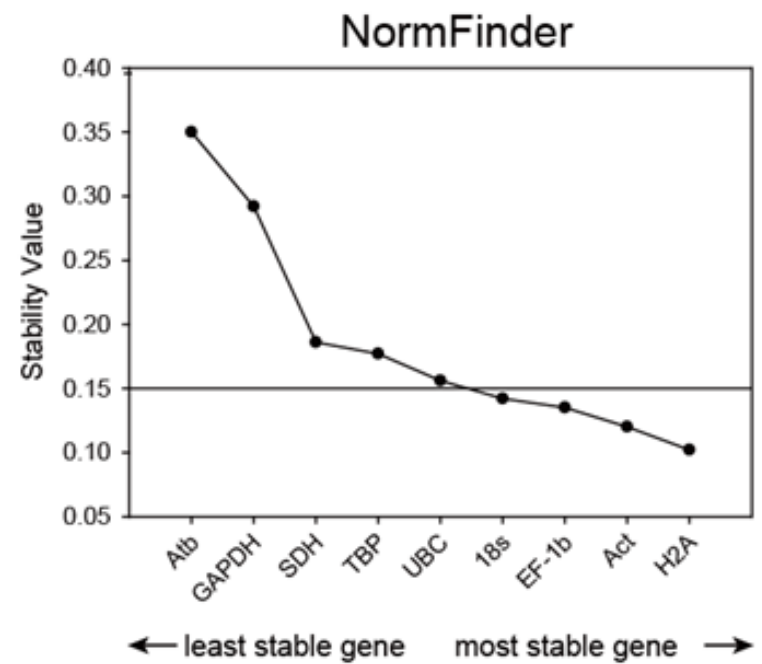

(D)

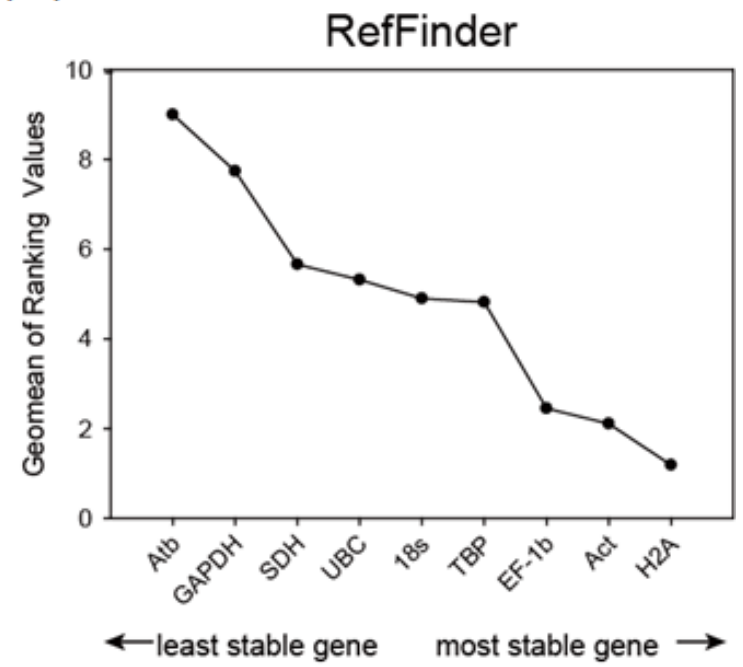

Figure 1

Expression stability of nine candidates for the normalization calculated by different algorithms for three different chemical (B[a]P, BPA, and $\mathrm{Hg}$ ) exposures. Reference genes are shown in ascending order of expression stability. (A) geNorm (stability M) (b) NormFinder, (C) BestKeeper coefficient of correlation, and (D) RefFinder, a geomean of ranking values integrating other methods. 
Figure 2

(A)

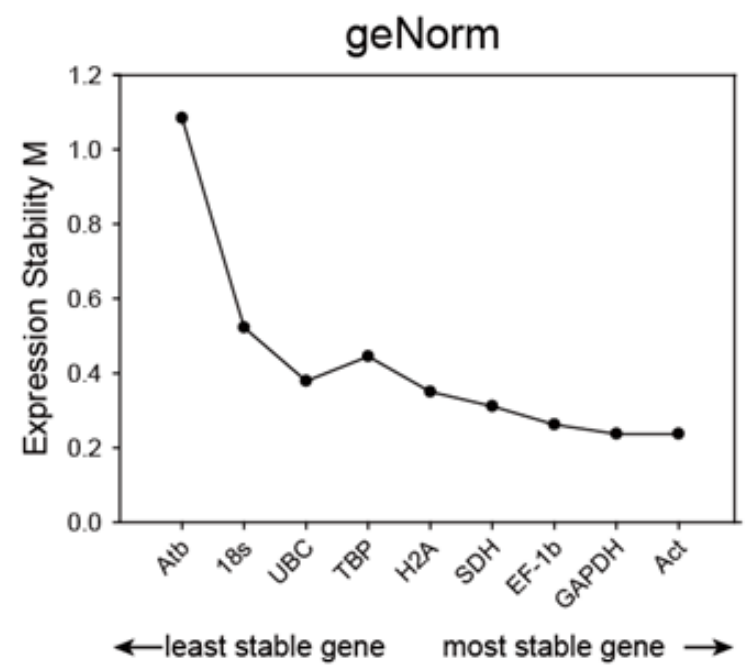

(C)

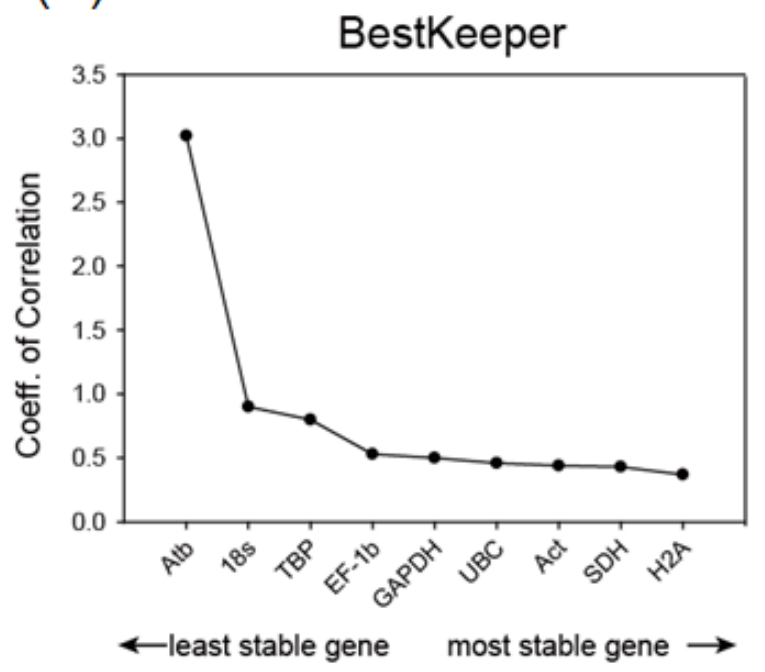

(B)

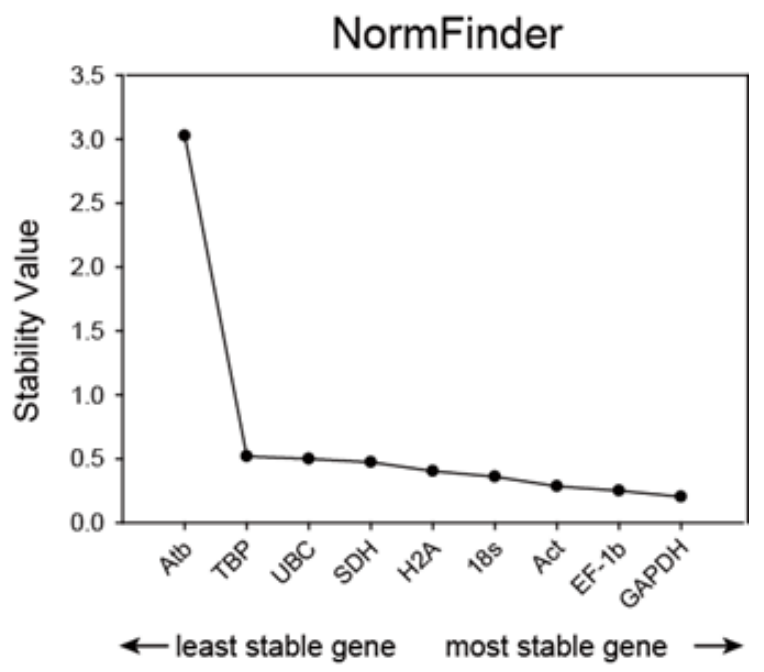

(D)

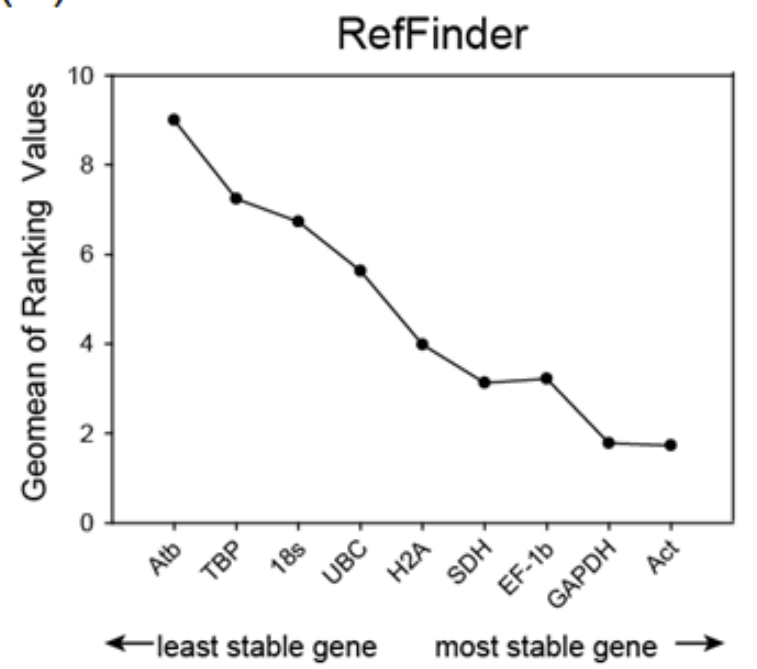

Figure 2

Assessment of nine putative reference genes of Diaphanosoma celebensis in different developmental ages (24h, 4d, 7d, and 10 d) by four different algorithms (A) geNorm, (B) NormFinder, (C) BestKeeper, and (D) RefFinder. Reference genes are shown in ascending order of expression stability. 
Figure 3

(A)

(B)
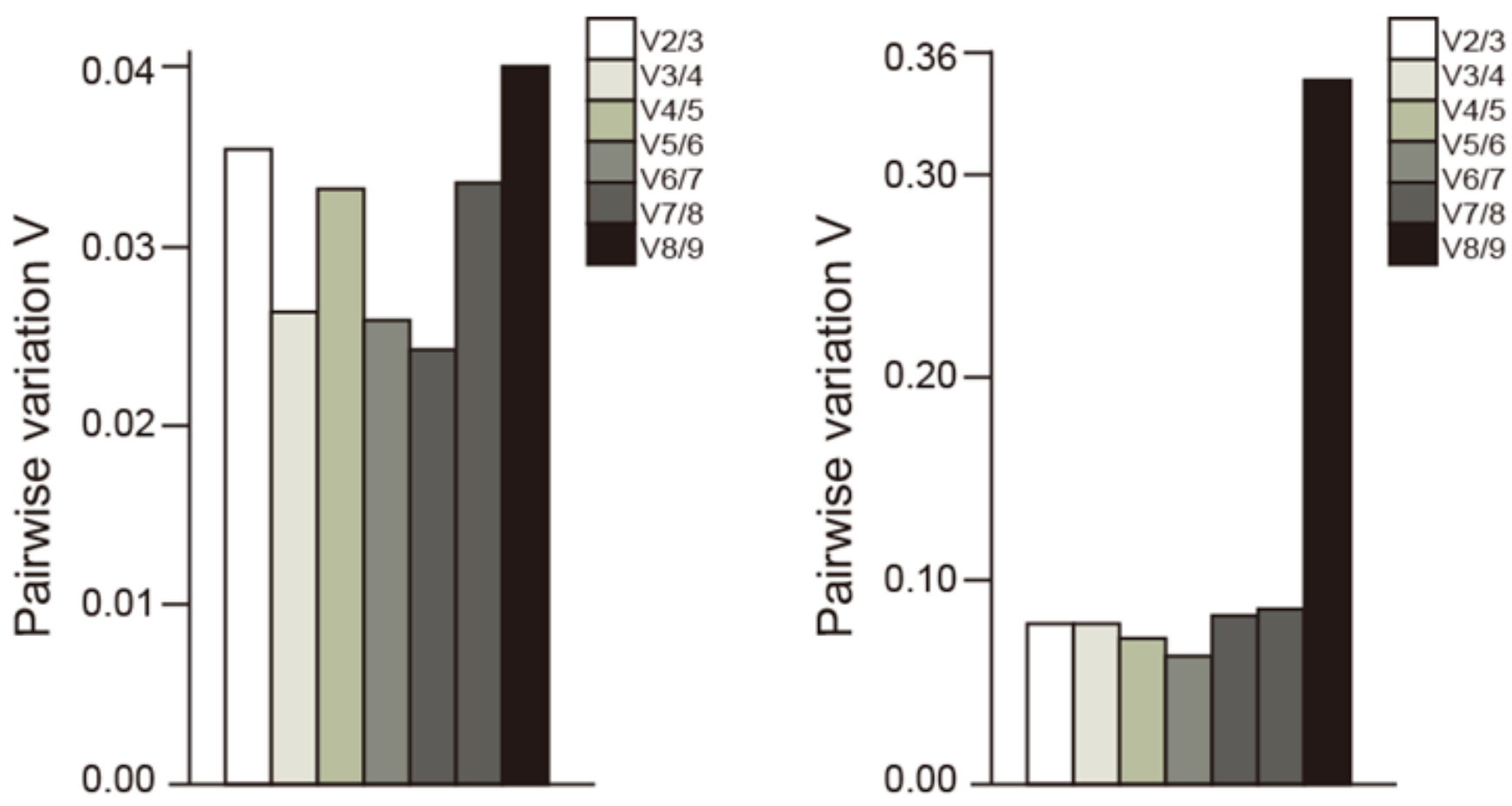

Figure 3

Pairwise variation for evaluating the optimal number of reference genes for accurate normalization $(V n / V n+1)$ in (A) chemical exposure and $(B)$ ages. The line indicates the cut-off value $(0.15)$, below which the inclusion of an additional reference gene is not required. 
Figure 4

(A)

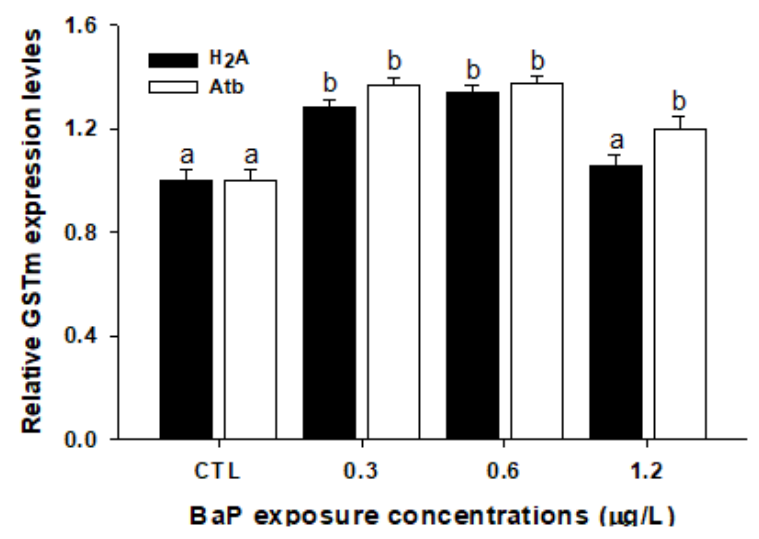

(B)

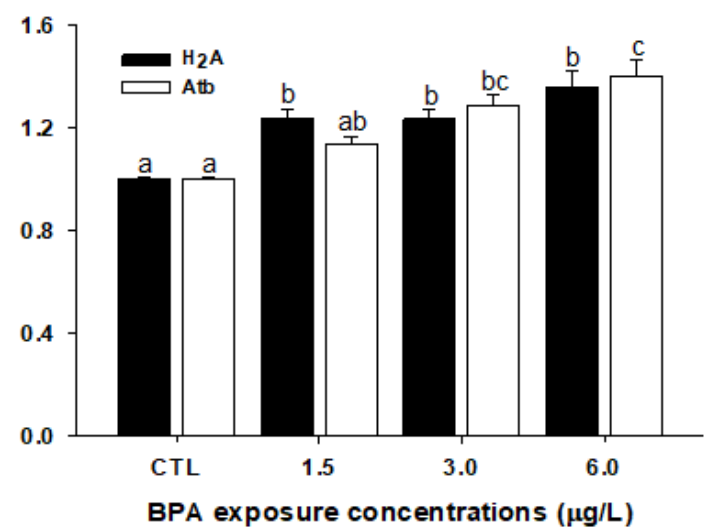

(C)

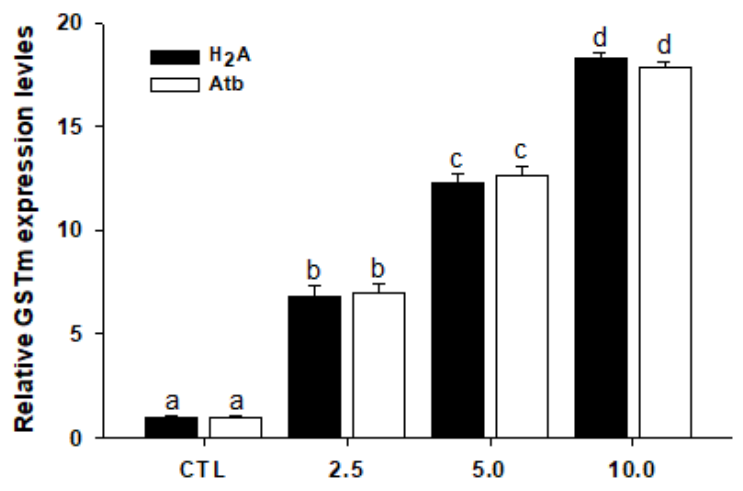

$\mathrm{Hg}$ exposure concentrations ( $\mu \mathrm{g} / \mathrm{L}$ )

Figure 4

The relative expression level of GSTmu was determined using select reference genes, including the most $(\mathrm{H} 2 \mathrm{~A})$ or least stable (Atb) reference genes, for normalization in the brackish water flea D. celebensis exposed to (A) B[a]P, (B) BPA, and (C) Hg. Different letters indicate significant differences between groups using different reference genes (ANOVA, Tukey's post-hoc analysis, $p<0.05$ ). 
Figure 5

(A

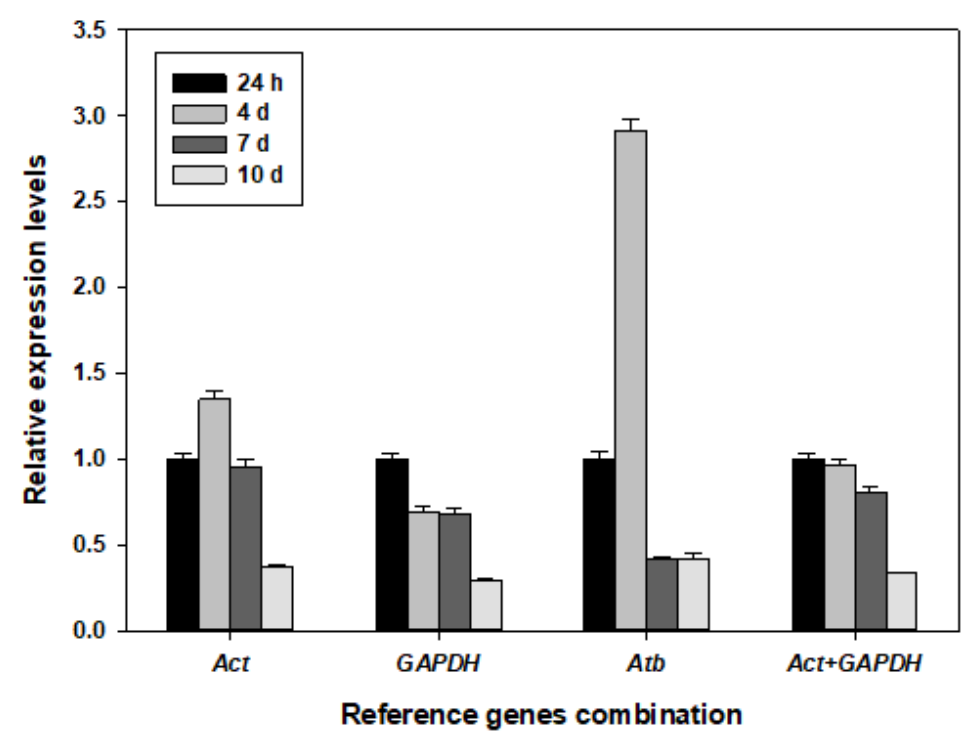

(B)

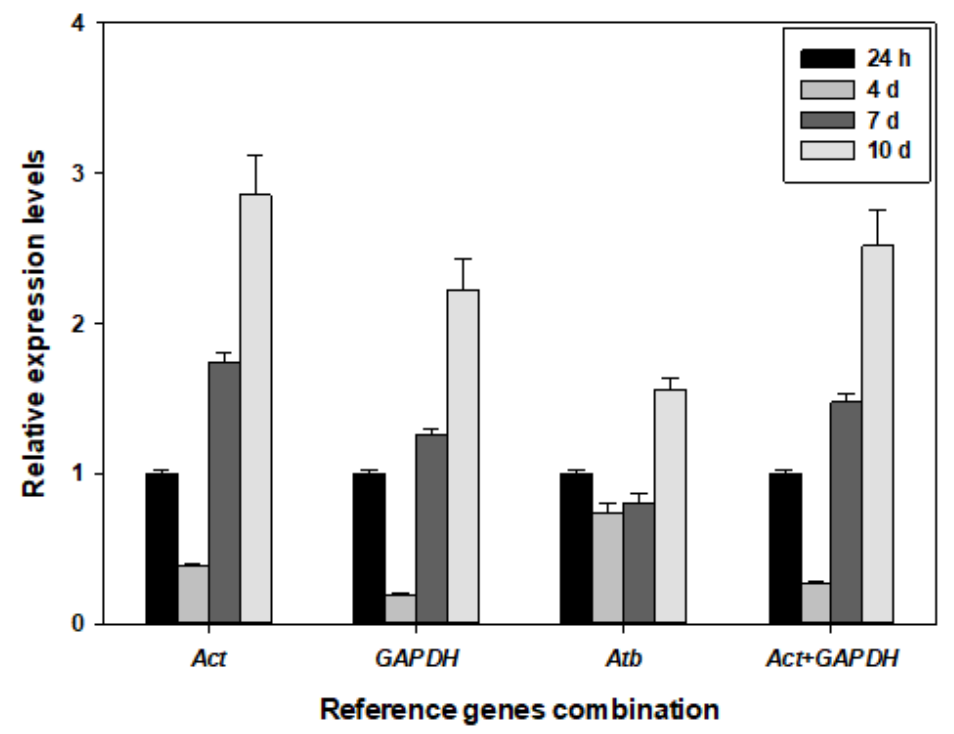

Figure 5

Relative quantification of (A) GSTsigma and (B) EcRA expression in D. celebensis at different ages, $24 \mathrm{~h}, 4 \mathrm{~d}, 7 \mathrm{~d}$, and $10 \mathrm{~d}$. The error bars represent the standard errors of the means of three biological replicates. Different letters and asterisks indicate significantly different expressions compared to the $24 \mathrm{~h}$ sample (ANOVA, $p<0.05$ ) and differences under different normalizations of the reference gene at expression levels for the same age, respectively (t-test, $p<0.05)$.

\section{Supplementary Files}


This is a list of supplementary files associated with this preprint. Click to download.

- SupplementaryInformationSciRep.docx 